\title{
Corpus
}

Archivos virtuales de la alteridad americana

Vol 4, No 2 2014

Julio / Diciembre 2014

\section{PHRASES SELECTAS: Un diccionario manuscrito castellano-guaraní anónimo}

\section{Graciela Chamorro}

\section{OpenEdition}

\section{Journals}

\section{Electronic version}

URL: http://journals.openedition.org/corpusarchivos/1309

DOI: 10.4000/corpusarchivos.1309

ISSN: $1853-8037$

\section{Publisher}

Diego Escolar

\section{Electronic reference}

Graciela Chamorro, "PHRASES SELECTAS: Un diccionario manuscrito castellano-guaraní anónimo », Corpus [En línea], Vol 4, No 2 | 2014, Publicado el 22 diciembre 2014, consultado el 30 abril 2019. URL : http://journals.openedition.org/corpusarchivos/1309; DOI : 10.4000/corpusarchivos.1309

This text was automatically generated on 30 April 2019

Licencia Creative Commons: Atribución-NoComercial 2.5 Argentina (CC BY-NC 2.5 AR) 


\title{
PHRASES SELECTAS: Un diccionario manuscrito castellano-guaraní anónimo
}

\author{
Graciela Chamorro
}

\section{EDITOR'S NOTE}

Fecha de recepción del original: 05/09/2014

Fecha de aceptación para publicación: 29/10/2014

1 La obra que es objeto de estudio de este artículo se titula "Phrases selectas y modos de hablar escogidos y usados en la Lengua Guaraní. Sacadas del Thesoro escondido que compuso el venerable padre Antonio Ruiz de nuestra compañía de Jesús para consuelo y alivio de los fervorosos misioneros principiantes en la dicha lengua"'. Trabajamos aquí con el ejemplar manuscrito que se encuentra en el Museo Mitre de Buenos Aires, bajo la referencia $14 / 4 / 41^{2}$. El diccionario propiamente dicho va de la página 1 a la 633 . Los datos son puestos a dos columnas, por orden alfabético. Es un diccionario bilingüe castellano- 
guaraní, fechado en 1687, en la reducción de San Francisco Javier, situado a orillas del río Uruguay $^{3}$, hoy Argentina.

IMAGEN N ${ }^{0} 1$ Frontispicio de las Phrases Selectas

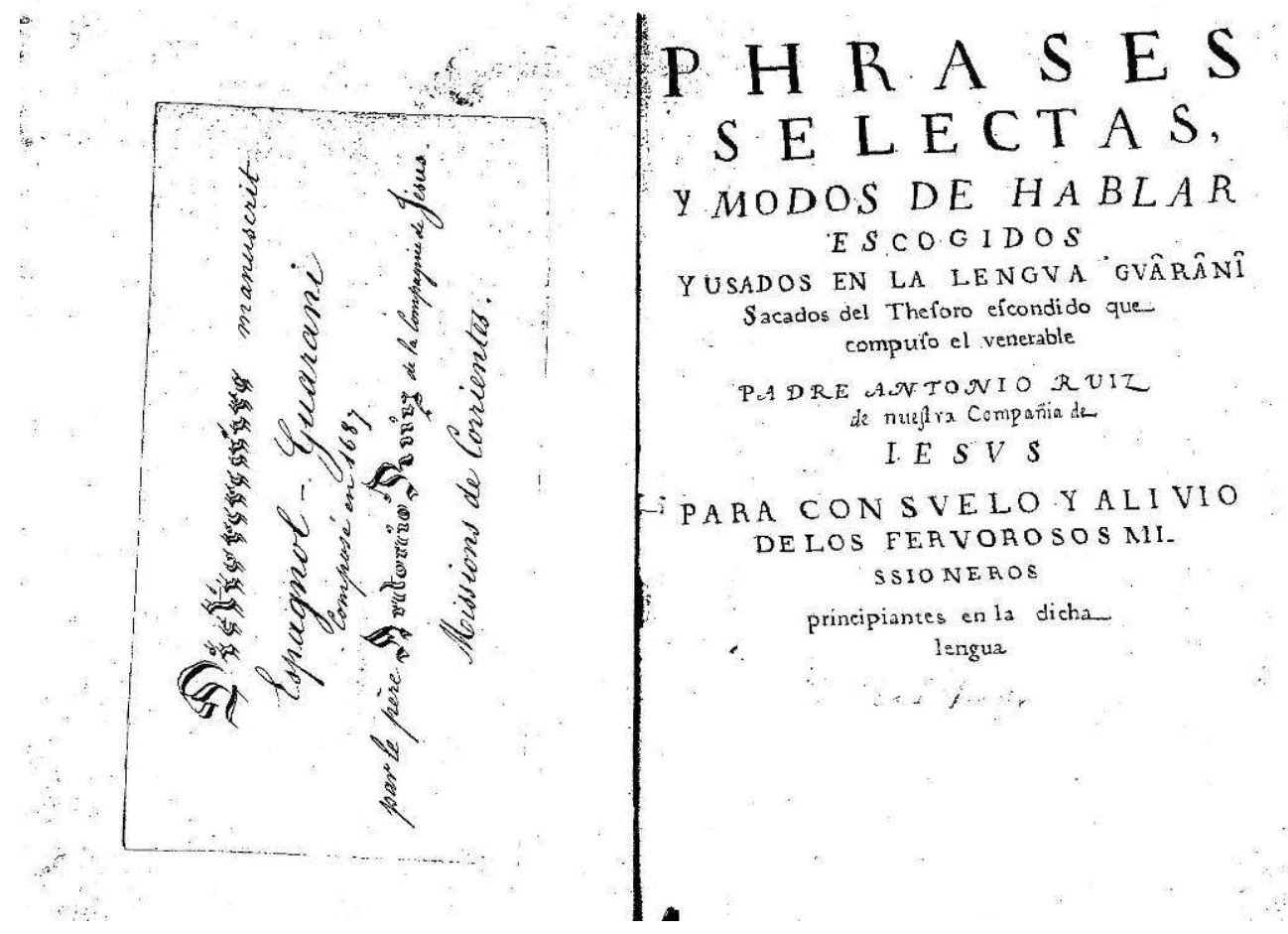

2 En la parte superior de la portada, con otra letra y subrayado consta una inscripción no muy clara, entendiéndose aproximadamente "es del P. Ramila" (Documenta Jesuítica 2000, p. 9). Siguen seis páginas en blanco, aunque en dos de ellas hay inscripciones ilegibles. El diccionario es precedido por dos textos escritos por el autor, que ocupan tres hojas no numeradas. El primero, una especie de dedicatoria, es dirigido A los fervorosos y apostólicos padres misioneros de la Compañía de Jesús en las Provincias del Paraná y Uruguay. El segundo se titula Amigo en Cristo y benévolo lector. Al final del diccionario está el Índice de aqueste vocabulario, para que con facilidad halles el vocablo que deseas saber, de cuatro páginas (más una en blanco) y una lista de cinco páginas (más una blanca) titulada Varios vocablos, $y$ modos de hablar no usados en San Xavier, ni en Santa María, que el autor "por si acaso fueren usados en alguna parte de estas reducciones" los puso citando "con fidelidad la hoja y columna del Tesoro del Venerable Padre Antonio Ruiz".

3 En este artículo nos proponemos presentar este documento, deteniéndonos primeramente sobre el debate en torno de su autoría. Luego deseamos mostrar cómo la obra fue construida, comparándola para ello con el Tesoro de Ruiz de Montoya. Por fin, presentaremos la estructura del manuscrito y el contenido de algunos temas, marcando las posibilidades de uso del documento en la investigación de la historia y antropología de la lengua guaraní y de sus hablantes.

\section{Autoría}

Las Phrases Selectas son adjudicadas a Pablo Restivo ${ }^{4}$ (Barbosa 1956, p. 18; Melià 1969, II, IV-V; 1992, p. 31; 2003, p. 115; Neumann 2005, p. 46; Rodríguez-Alcalá 2007, p. 124-125), porque la obra es contemporánea de otros dos notables manuscritos firmados por Blas 
Pretovio, nombre que consta en algunos documentos de la época, como el anagrama ${ }^{5}$ de Pablo Restivo. De modo que adjudicar la obra a Pretovio es adjudicarla también a Restivo.

IMAGEN N² 2. SEgún BARTOLOMÉ MITRE, BLAS PRETOVIO ES EL ANAgRAMA DE PABLo RESTIVO

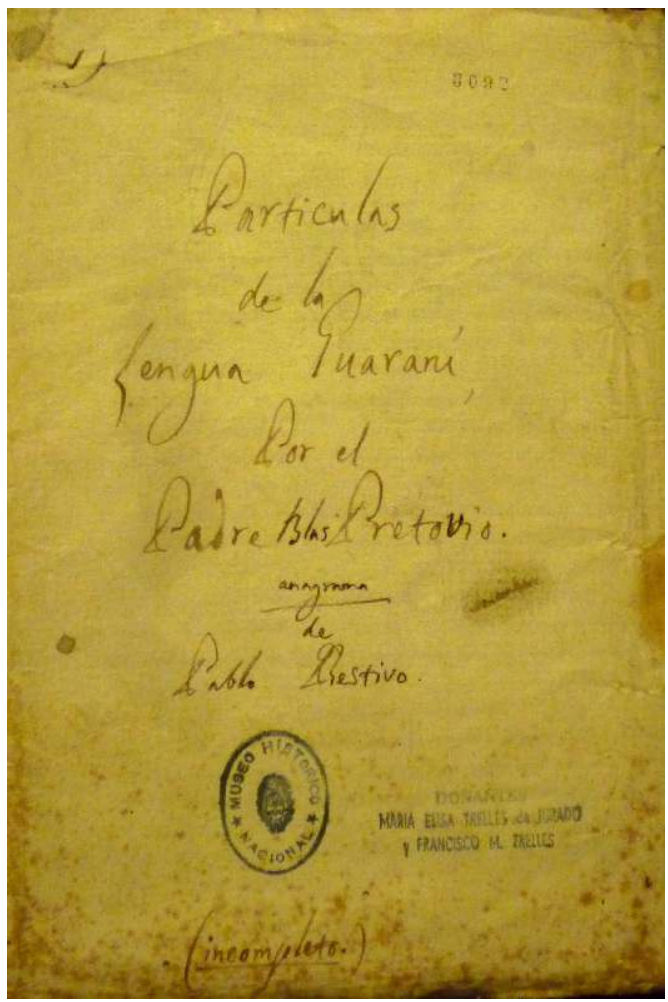

Pero las Phrases Selectas no traen en la carátula sino la indicación de que ellas fueron seleccionadas del Tesoro de Antonio Ruiz de Montoya. De modo que en la ficha catalográfica del Museo Mitre el manuscrito consta bajo la autoría de Ruiz de Montoya y como si hubiese sido compuesto en 1639, fecha de la primera publicación del Tesoro.

Nro. de Registro: 4327

Ruiz de Montoya, Antonio

Phrases selectas y modos de hablar escogidos y usados en la lengua guaraní, sacados del Tesoro Escondido que compuso el venerable padre Antonio Ruiz de nuestra Compañía de Jesús para consuelo y alivio de los fervorosos misioneros principiantes en la dicha lengua

633 p. $-22 \mathrm{~cm}$

Volumen manuscrito. Obra compuesta en 1639

La obra trae en la parte interna de la tapa un rótulo en francés con la inscripción:

Dictionnaire manuscrit

Espagnol - Guarani

Composé en 1687

Par le père Antonio Ruiz de la Compagnie de Jésus

Missions de Corrientes.

7 La caligrafía del rótulo es muy distinta de la del cuerpo del manuscrito; parece ser del siglo XIX y fue pegado mucho después sobre el documento. El hecho de que el rótulo esté escrito en francés sugiere que el material estuvo en poder de bibliófilos francófonos o de personas afiliadas de alguna forma a ese idioma.

8 La fecha 1687 aparece también al final de la dedicatoria $A$ los fervorosos y apostólicos, que está firmada en la reducción de San Francisco Javier, el 27 de septiembre de ese año. Esta 
fecha es incompatible con la supuesta autoría de Restivo, ya que él llegó a Buenos Aires recién en 1691 y a las reducciones jesuíticas de Paraguay solamente en 1694 (Storni 1980, p. 236). Bartomeu Melià supone que la fecha puesta en el manuscrito podría tratarse de un error del copista o de los catalogadores, que habrán transcrito 8 en lugar de 9 (Melià 2003, p. 331-332). Si esta solución fuere históricamente aceptable, las Phrases Selectas podrían ser de Pablo Restivo, que en 1697 ya vivía hacía casi cuatro años en las reducciones jesuíticas del Paraguay. manuscrito, pues el autor menciona varias veces su interacción in situ con los indígenas reducidos, como en el pasaje abajo:

"No digo esto sin alguna experiencia, porque en San Javier se usan unos modos de hablar tan particulares, que valiéndome yo de ellos en Santa María, y en otros pueblos, no me entendían, y fue necesario mudar de rumbo, y buscar otros usuales en aquel pueblo. Lo mismo suele acontecer en los confesionarios, donde se oyen particulares modos propios de aquel pueblo y no de otros" (Phrases Selectas, primera página de Amigo en Cristo y Benévolo Lector).

10 En otros pasajes, el autor registra su constatación de que el guaraní del Tesoro no era conocido por todos y que no se hablaba el guaraní de una única manera sino que había una diversidad lingüística en los pueblos de indios reducidos. Afirma: "leyendo algunos párrafos [del Tesoro de Ruiz de Montoya] a los naturales, no me entendían". De modo que "si en distancia de solo cuatro leguas se hallan modos de hablar tan diversos entre sí, qué será en distancia de tantas leguas, cuantas anduvo el venerable padre y de tantas parcialidades, cuantas comunidades y pueblos tan diversos, que merecieron su cuidado y asistencia". Y el autor da varios ejemplos en el cuerpo del diccionario. Así, en la entrada "carne gorda", escribe: "explícase con términos usados en San Javier" y lista tres vocablos y sus ocurrencias en frases que corresponden a la entrada: mesẽ, so'o mesẽ ; kambeũ, so'o kambeũ; joy, ijoy so'o. El autor concluye: "Estos tres modos de hablar no los he visto, ni hallado en el Thesoro, pero los usan los de San Javier y Santa María" (Phrases Selectas, 168).

11 Una cosa sí es clara y es que el autor no era ni hispano-hablante ni guaraní-hablante. En su sexta advertencia a su "benévolo lector", escribe: "cuando encontrares algunos barbarismos en el idioma castellano, o guaraní, no te admires; porque ninguno de ellos me es connatural, sino aprendido". Este era precisamente el caso de Restivo, pero también de muchos otros misioneros de la época ${ }^{6}$.

12 Ahora bien, volviendo a la propuesta de Bartomeu Melià de fechar las Phrases Selectas en 1697, para integrarla a los manuscritos en guaraní de 1696 y 1697, cabe precisar que estos son el Arte de la lengua guaraní por el P. Blas Pretovio de la Compañía de Jesús ${ }^{7}$, firmada en el Uruguay $^{8}$ y el manuscrito autógrafo Partículas de la lengua Guaraní, de $1697^{9}$.

Si el manuscrito Phrases Selectas fuese de hecho de Pretovio y este fuese el mismo Restivo, él sería el autor de la trilogía Arte-Vocabulario-Phrases Selectas , que no solo reedita las obras montoyanas sino que también reafirma la autoridad del misionero lingüista Ruiz de Montoya. Esta idea es estéticamente atrayente, puesto que un siglo después de Montoya, se habría entonces levantado otro gran príncipe de la lengua que revitalizó el legado ya existente. Pero todo esto no pasa de ser conjeturas, no por dudar de que Blas Pretovio sea el anagrama de Pablo Restivo, sino por no constar el nombre de Blas Pretovio en parte alguna del manuscrito.

Para Cerno y Obermeier, intentar equiparar el pseudónimo Blas Pretovio con la persona de Restivo revela que "existe en la investigación del guaraní jesuítico la tendencia de 
descuidar el aporte de varios jesuitas anónimos dentro de una obra tan vasta como la lingüística del guaraní reduccional". Eso expresa -prosiguen los autores- que existe "una visión unilateral del guaraní reduccional, creada a partir de la focalización en la obra lingüística de Montoya", que ha servido para crear la idea de un "guaraní clásico", "unificado y estandarizado, descuidando los fenómenos de variación bien documentados en manuscritos hasta hoy no editados como las Phrases Selectas" (Cerno y Obermeier 2013, p. 43, nota 7).

En nuestra opinión, para avanzar en el tema de la autoría de las Phrases Selectas, necesitamos una biografía más detallada de Pablo Restivo, comparar las Phrases Selectas con el Arte y Vocabulario de 1722 y 1724 respectivamente, así como con los manuscritos firmados por Pretovio, que supuestamente sirvieron de base para el Arte y el Vocabulario. Precisamos aclarar el tema del uso de anagramas y pseudónimos entre los jesuitas, recopilar más datos para confirmar o no la correspondencia entre Blas Pretovio y Pablo Restivo, el perfil de los jesuitas de las reducciones llamadas del Paraná y del Uruguay, potenciales autores de la obra, que entonces se habrían escondido bajo el pseudónimo Blas Pretovio. En todo caso, cabe aclarar que con este nombre no figura ningún jesuita en los catálogos sobre los misioneros jesuitas en el Paraguay (Storni 1980).

De modo que mientras no tengamos más datos, nos parece prudente mantener las Phrases Selectas como de autoría anónima, lo que no es del todo raro entre los jesuitas de esa época. Seglinde Falkinger $(2008$, p. 1,8$)$ apunta en ese sentido: los jesuitas dejaron varios manuscritos sin firma en la época colonial, escribiendo "para mayor Gloria de Dios". El propio Restivo parece no haber firmado el Vocabulario de la lengua guaraní. El autor del diccionario está indicado en la tapa como "otro religioso de la misma compañía". Solamente la Facultas R. P. Provincialis dada por el padre Ludovicus à Roca menciona a "P. Paulo Restivo, Societatis IESV" como autor (Restivo 1722, no numerado).

En el caso de las Phrases Selectas, el autor pudo no haber firmado porque no se consideraba autor. Reconocía en la obra la prevalencia de la autoría de Ruiz de Montoya y de los indígenas que cedieron ejemplos contemporáneos para el diccionario. Es lo que parecen indicar las palabras del autor A los fervorosos y apostólicos padres misioneros...: "les ofrezco humilde, y rendido el Tesoro opulentísimo del V. Pe. Antonio Ruiz reducido a más fácil método".

\section{"Pasar a limpio el Tesoro"}

¿Cómo fueron escritas las Phrases Selectas ${ }^{10}$ ? En este acápite queremos responder a esa pregunta, buscando por qué, a partir de qué, con cuáles criterios, para qué y en qué contexto el autor escribió esta obra.

En cuanto a los motivos del autor, consta que lo hizo a pedido y bajo consejo de algunos padres "para ayudar en algo a los nuevos misioneros", que el autor llama "principiantes" $(P h S, 2)$. Él se propuso actualizar y reestructurar el diccionario guaraní-español de Montoya porque su trabajo con los indígenas le mostró que la obra estaba desactualizada y porque sus compañeros de misión no conseguían aprovechar bien este diccionario. En ese medio, decidió "pasar a limpio" el Tesoro "escogiendo los términos más usados y dejando los vocablos [...] que no se entienden". propias de la lengua. En las páginas dirigidas al "Amigo en Christo y benévolo lector", 
escribe que a los principiantes les es muy difícil encontrar el tesoro escondido en el diccionario de Montoya, "ya por los yerros de la imprenta, ya también por algunos vocablos y modos de hablar [...] propios de los naturales, pero ya per no usum, se han anticuado y hecho casi inteligibles (sic)". Reitera lo que el propio Montoya ya advirtiera en su obra, que "hay términos que se usan en unos pueblos que no son usados en otros"11.

El autor dio a entender que es por causa de esos arcaísmos que los ejemplos del Tesoro se tornaron ininteligibles. Ya en el prefacio de las PhS, el autor confiesa "haber oído" críticas al Tesoro de Montoya entre los jesuitas. Por la dificultad en comprender la obra, consideraban ser "tiempo perdido leerle". Esto sugiere que el autor del manuscrito en foco estaba preocupado por la situación lingüística en los pueblos jesuíticos, donde el legado de Montoya ya no era suficiente para atender las demandas actuales. Habla del desuso de "términos y vocablos", pero ciertamente no se trataba solo de cambios lexicales, sino también de cambios más complejos, sobreentendidos en las frases "modos de hablar", "modos de hablar tan particulares", "particulares modos propios [de hablar] de aquel pueblo", que dificultaban la comunicación, pues el autor afirma: "no me entendían". Según Rodríguez-Alcalá queda muy claro en estos pasajes que

"a diferencia de otras tradiciones gramaticales orientadas por una idea patrimonial de la lengua, como es el caso de los vernáculos europeos, el problema que suscita el cambio lingüístico en las gramáticas de guaraní no es el de la 'corrupción' de un modelo valorizado de lengua cuya referencia se busca fijar, sino el carácter 'obsoleto' de una descripción 'arcaica' y 'desfasada' con relación al uso presente que pierde por ello utilidad" (Rodríguez-Alcalá 2013, p. 513).

De lo expuesto hasta aquí, el autor del manuscrito parece haber tenido dos criterios: 1) escoger los términos más usados, dejando fuera los vocablos que ya no se entendían, y 2) registrar los vocablos particulares en uso en una reducción o pueblo, para que cuando el misionero estuviera allá pudiera entender a sus interlocutores y ser entendido por ellos. En el primer caso, el criterio es temporal, pues se pretende evitar los arcaísmos y registrar los vocablos y las formas de hablar actuales. El segundo criterio es espacial. En ambos casos, el autor se apoya en la lógica del uso. El segundo criterio ya había sido observado por Montoya en su Tesoro, unas ocho décadas antes. En sus Advertencias se lee que algunos vocablos eran más usados en unas partes que en otras y que si él los registra es "para que no se haga nuevo al que oye en una parte el vocablo que en otra no oyó" ( Tesoro $\left.{ }^{12}, 1\right)$.

Ahora bien, ¿en qué se ha basado el autor de PhS? Él adjudica constantemente su pericia en la lengua guaraní a su maestro, "el venerable padre Antonio Ruiz". Sin embargo, en esta época había en las reducciones jesuíticas del Paraguay misionarios e indígenas que conocían bien la lengua guaraní y escribían en esa lengua; además había obras en guaraní heredadas de otras generaciones. Como se puede leer en el Arte de Restivo, los jesuitas contaban con la obra de Alonzo de Aragona, los apuntes de Simón Bandini -“príncipe de esta lengua"- y varias composiciones de "indios muy capaces". A ese respecto Restivo escribió:

“me puse de propósito á juntar en uno [en su obrita] lo más selecto que en cada uno dellos he hallado [...] en la cual he tambien añadido muchas otras anotaciones y reglas, que yo he sacado de varias composiciones de Indios y del P. Simón Bandini, tenido comunmente por Príncipe desta lengua, habiéndolas primero averiguado con Indios muy capaces" (Restivo [1724] 1996, p. 1).

24 En su Arte, Restivo cita, además de Ruiz y Bandini, a Mendoza, Pompeyo, Insauralde, Martinez y Nicolás Yapuguay, elogiándolos con la mención "todos son de primera clase" 
(Restivo [1724] 1996, p. 1). Las obras de todos estos autores y de los colaboradores anónimos ciertamente fueron consultadas por el autor del manuscrito en foco. Además, el autor recogió datos para su obra directamente con los hablantes indígenas de las reducciones, teniendo como referencia el modo de hablar de Santa María la Mayor y San Javier. De modo que, al contrario de lo que dice el título, las frases no son seleccionadas solamente del Tesoro de Ruiz de Montoya.

Las PhS, como el conjunto del trabajo lingüístico de Ruiz de Montoya $(1639,1640)$ y de Restivo (1722, 1724), tenían dos objetivos: 1) enseñar la lengua guaraní a los misioneros extranjeros, interlocutores del discurso gramatical; la obra era, en ese sentido, como un libro didáctico para aprender el nuevo idioma; 2) catequizar en guaraní; las PhS contienen para ese fin varios aspectos de la doctrina cristiana, que los misioneros aprendían para instruir y corregir a los indígenas y que los indígenas escuchaban o leían gracias a los misioneros. Como en las Artes, el indígena, hablante primero de la lengua, aparece en las PhS como locutor de los ejemplos, como aquel que dice cómo se usa la lengua (RodríguezAlcalá y Horta 2008). Estas obras metalingüísticas no eran solo libros de doctrina (de lo que se debía decir o no se debía decir en el campo religioso), ni solo registros de la lengua cotidiana (Chamorro 2009, p. 99-100). En general, cada artículo de los diccionarios presenta usos de la vida ordinaria y usos en el registro especializado de la religión católica. Obsérvese al respecto, en el cuadro 1 del anexo (véase archivo en pdf en Documentos anexos a este artículo), el primer artículo del Tesoro, el lexema ' $a^{13}$, que en la primera acepción significa 'coger/sacar' e 'imitar' $(T, 3)$ y los artículos correspondientes en las PhS $(187,401)$, coger e imitar respectivamente. Volveremos a este tema al hablar del contenido de la obra.

En cuanto al contexto histórico inmediato de la producción de las PhS, cabe destacar que en las últimas décadas del siglo XVII las reducciones dirigidas por los jesuitas en el Paraguay eran socialmente más estables y prósperas. Ellas estaban lejos del camino de los bandeirantes, con mucho menos ataques imprevistos de indígenas "hostiles", casi sin rebeliones entre los indios reducidos, con las nuevas enfermedades controladas, la demografía ${ }^{14}$ estabilizada, la "nobleza" indígena a favor de los misioneros y la economía en crecimiento. Esto permitió a los ignacianos intensificar las actividades culturales en las reducciones, dedicarse a escribir y formar a los indígenas en las nuevas especialidades que requerían las nuevas formas de convivialidad y vida religiosa (Melià 2003, p. 112; Wilde 2009). Inquirido el padre Bernardo Nusdorffer, en 1737, sobre la no fundación de nuevas reducciones, él habría respondido que la conservación de una reducción "era una conquista continuada" (Furlong 1962, p. 629).

En el ámbito de las letras, cabe recordar que si bien desde $1630^{15}$ los jesuitas del Paraguay venían reivindicando el envío de una imprenta y de un misionero para imprimir libros en guaraní en las reducciones, tal solicitud no se concretó sino setenta años después. ¿Qué hicieron los jesuitas entretanto? Unos pocos imprimieron sus obras en España, como Montoya. Otros enseñaron a los indígenas a copiar a mano, en tinta, sus manuscritos y algunos libros impresos de origen europeo. De modo que las PhS fueron escritas en ese contexto. La imprenta fue instalada en las reducciones a fines del siglo XVII ${ }^{16}$, cuando ya circulaba una serie de manuscritos en los pueblos de indios. Además de los ya citados en el acápite anterior, hay otros en la lista de gramáticas, diccionarios, catecismos y otras obras de contenido religioso presentada por Bartomeu Melià (2003, p. 331-335, 341-343, 354-357), juntamente con obras de otras décadas. Había también manuscritos en guaraní relativos a la vida ordinaria. En fechas cercanas a las PhS están el Diario de guerra 
$(1704-1705)^{17}$, Diálogos en Guaraní, llamados Manuscrito Gülich ${ }^{18}$, y un texto sobre hierbas medicinales, Pohã Ñanã o Códice Villodas $(1725)^{19}$. Entre las obras manuscritas en español en el ámbito de la vida ordinaria están la Materia Médica Misionera $(1710)^{20}$ y Libro de Cirugía (1725) ${ }^{21}$ del hermano jesuita Pedro Montenegro.

\section{Estructura de las PhS}

28 Las únicas divisiones en las 633 páginas del manuscrito son las que constan en el índice. Ej. A ante B, A ante C, A ante Ç, A ante Ch, etc. Cada una de estas divisiones es marcada por una letra estilizada y un entrelineado mayor. Además de las 633 páginas numeradas, las PhS tienen, aparte de la tapa, 16 páginas de texto no numeradas más seis páginas en blanco. Ya el Tesoro tiene 408 hojas, folios, a cuatro columnas, más diez páginas iniciales no 
paginadas. Como el Tesoro, las PhS están organizadas en dos columnas por página, como puede observarse en las imágenes siguientes.

IMAGEN No 3 - Artículo jahe'o [yaheó], 'Ilorar', en el Tesoro de Montoya

\begin{tabular}{|c|c|}
\hline LENGPA & $G V A R A N I$. \\
\hline 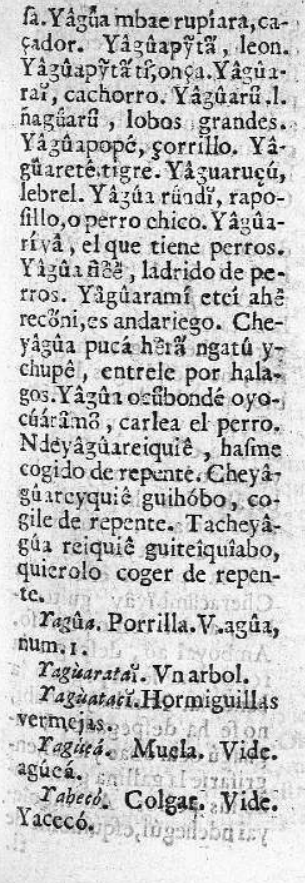 & 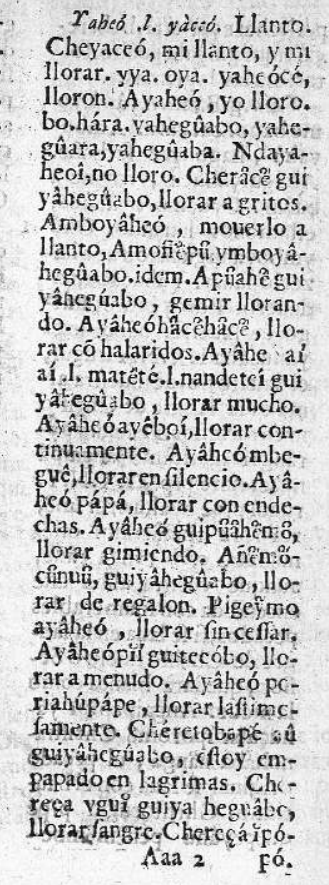 \\
\hline
\end{tabular}

IMAGEN Nº4 - Artículo 'llorar, llorón', jahe'o [yaheó], en las Phrases Selectas

$$
\begin{aligned}
& \text { 438. il. ente. } E \text {. } \\
& \text { uon! Araha Mollewo. Nacarahsi. }
\end{aligned}
$$

Il. inte. 0 .

II. anre. $0: N$. .

Lorax, lleron. Teçaibo. Li. Chesecailo. llo ro mucho. Aporoeco.ibo bo guircuo bo. Años llorădo. thevelar xamo abahe y thuge. Apuxo lisxav to al cance vide. Tecaibo. $\sim$ Hapirôt thesapirô.

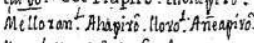
Llovo tha piro noteanpaypa papuera. lloxa tui pecasoos ? Oñea pió tế aña vetró menuara. Llo van tin remedio lospel infierns. Nide. Ha giró. Yaheo 't Cheya heo Millarto . Fyahè. Llorot:Ndayaheoit Notlore. Che racé guigahè bo. llovo agrime. Amboyaheo . Hago le llo rax. Amo ñefü y mbo yaheobo. Muebole allanto. Apuí he guingaheguabo. Gimo lloxambo :-Ayahes hati hate . Hovo con alarido. Aya hè ai ấ. lloro mucho. Ayaheo ayebos. Iloro continuamente? Azgabei mbeque. lloxo ensilen-

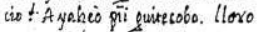
amenuoo t. Ay aheo poriahu hape. llo so lestinosamente therecan, ciringuing heà bo: Sueltanse melas lagximas. Vide Nahio - a Teçaquaripe. - Ndexefaquaxipe eyahe-
II. ante. $0 . \mathrm{N}$. guabo. Tienes los ojo empaparos de llovar, Nide- Tecaquaripe. no Teçânga : Cherecanga. Soy lloron. 1. Añemo écanga. Doy un lorart:Amoecanga . Hagole quellore, olloron. vide. Tecanga.

Cloues, ollo viznas, Itruia, nuevio velampaso, en. A mât:Amábe

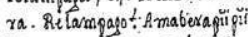
Relampaguear amenutoot: A mâtulnû. Trueno 1 . A má una ú remimo coñngulue. el hevido zel trueno, a-

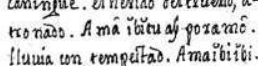
Continuo carua, o ersindet: A mánger. Agualloueviza! A mañoná Gromi20. A manioaú oji yusu. Granizo guesso. A mañoi qui. Ilocer. Amanoiqui ayin yucu. Caersotay graessast: Amá niogumai. No echan agua las nubes t-Amiangi piambro. Tempetitao de agua con ruidó: Amá. rempeitas de ajua con ruido. Ama-

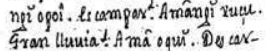
Lan las nubes. Amấ ogua araceâuxy me. flover con Sol, oria clesto. Amia

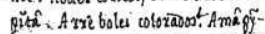
tĥ . Nabinoon. A má pỹumbi. दrá obscuridao del tiemapot. A má pyjú,
4. ante. A. 439 axa. Dia nublàoo ${ }^{2}$ Amápitú ibiruaj. Tempertas re agua gviento. 1. A máremi moáquyinguesa.. Cosan moiazia de lluvia : Amá räapa. Truenot I matixi . Rayo' Axa amá noasti. Ilunioso riempo. Nide. Amâ. n? 3 .

Bar ante. A.

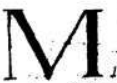

Mica moxya ysur Naviedat Caguiyi. Caguí yi ará. espersat Cogeñyigi răcu. Raila - Nide. Ca Quî́. noui vo vicue, Haso maca morra del caldot. Tivu minjaal. trita liquida la maca morra t-y napomón mineấ. lifa eppessa. lyaposimumineaul. Des lie la maca morra: 3 -

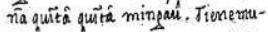
thos to leñorones la maca morya. 2. A humbixi y ña quáránguera. Des haso los toloñorsnes oela masa morra. Nide. Minzaü. $m$ Pindocure. Amó miñocuse. Hago maca morta, vide. Pinjocure ar Mbureè. Amo mbuxiè. Haso 45 in.

IMAGEN No5 - Artículo 'llorar', jahe'o [yaheó], en el Vocabulario de Montoya 


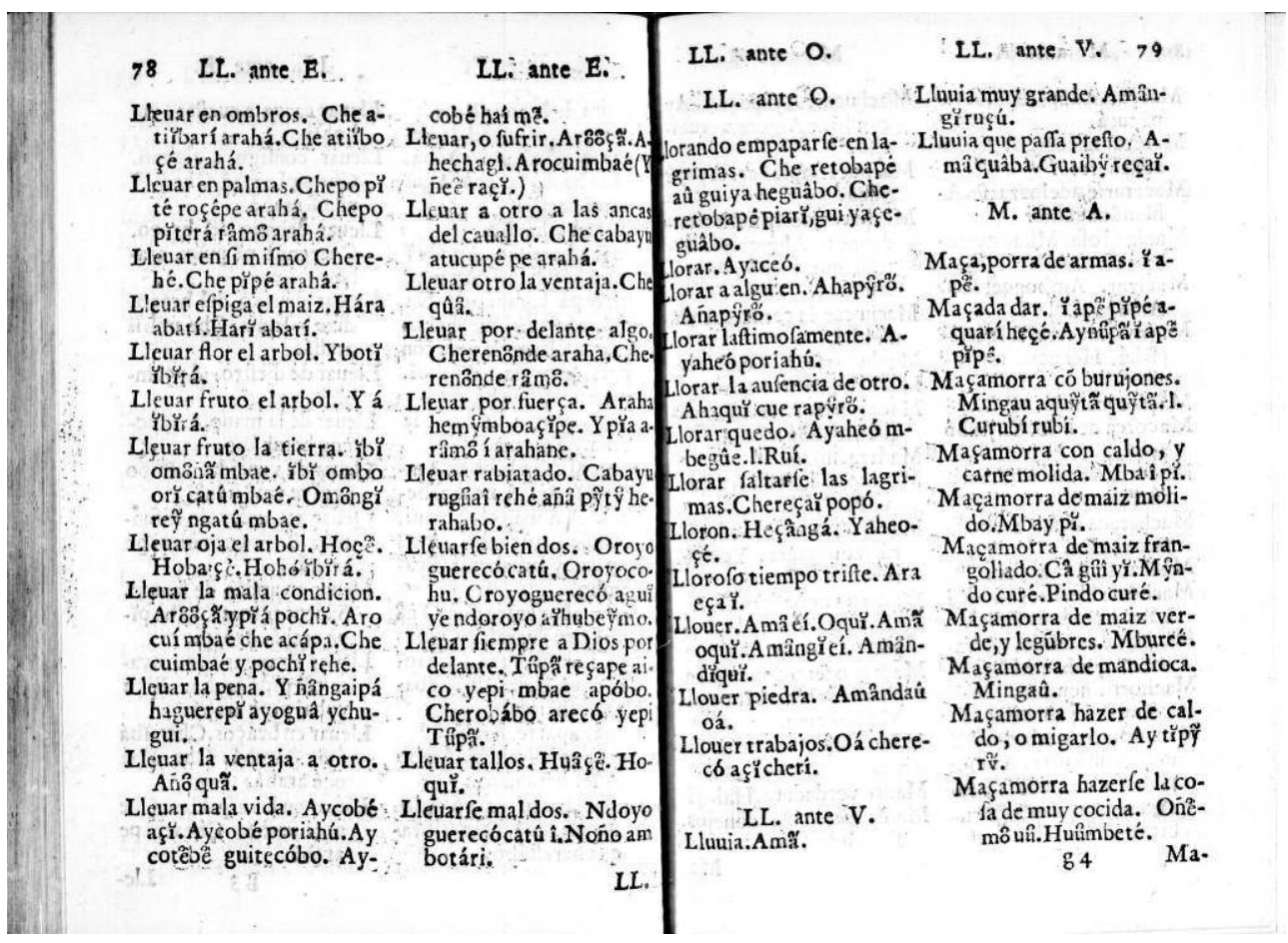

A propósito de la imagen número 5, considérese que el autor de las PhS no menciona el uso del Vocabulario de la Lengua Guaraní de Montoya, pero de hecho maneja esta obra al lado del Tesoro para organizar su material. De cierta forma podemos decir que él reestructura y simplifica ambos diccionarios en sus PhS. En el Tesoro, a las entradas en guaraní pueden seguir datos sobre la composición de las palabras y (los) significado(s) numerados del término con sus respectivos ejemplos en guaraní, traducidos al español a continuación. Este diccionario es considerado un tesoro precisamente por ser muy rico en ejemplos. El Vocabulario sólo da los términos equivalentes en guaraní con pocos o ningún ejemplo y explicaciones.

Montoya orienta a sus lectores a buscar primero en el Vocabulario (castellano-guaraní) el vocablo que les interesa y los remite después al Tesoro (guaraní-castellano) para acceder a más explicaciones y ejemplos. En las PhS las entradas principales son por el castellano. Cada término es separado del término, o los términos, correspondiente/s en guaraní, generalmente, por un punto o una coma. El término guaraní aparece "en absoluto", esto es, "sin nota de persona alguna", o sea, supuestamente sin las variaciones resultantes de la posición del término en una frase. Siguen los ejemplos, a los cuales se les da entrada por el guaraní; en seguida, las traducciones correspondientes en castellano. Al final del artículo, el autor escribe, generalmente, el vocablo latino Vide seguido del término guaraní "en absoluto", remitiendo con ello a sus lectores al Tesoro de Montoya, en caso de que quieran acceder a "más modos de hablar". Así, el Tesoro está omnipresente en las PhS. Consultar al respecto el cuadro 2, del anexo (véase archivo en pdf en Documentos anexos a este artículo).

De modo que si queremos comparar el contenido de algunos conceptos, vocablos o prácticas, la estructura de las PhS nos obliga generalmente a hacer la búsqueda por más de un término, pues lo que el Tesoro reúne en un artículo con entrada en guaraní consta en las PhS en más de una entrada y lo que las PhS reúnen en un artículo entrando por el castellano, consta en el Tesoro en entradas distintas. Por ejemplo, en el primer artículo del Tesoro $(T, 03)$ consta el vocablo ' $a$, con el significado de 'coger' e 'imitar', en su segunda 
acepción; en las PhS hay que buscar las entradas 'coger' (PhS, 187), 'imitar' (PhS, 401) y sus sinónimos, si se quiere comparar ambas fuentes.

Lo mismo ocurre con "canasta y sus variedades", término y expresión de entrada en las PhS. El autor nos da los significados ajaka, panakũ y urukuru seguidos de sus respectivos ejemplos. Si queremos ver lo que consta en el Tesoro al respecto, tenemos que hacer la búsqueda por cada uno de los tres términos y de los otros que aparecen solo en el cuerpo del artículo.

En algunos casos, como al tratar de "bestialidad", el párrafo termina con "vide thes. fol. 362. colum. 4 \$2" (PhS, 122), remitiendo con eso el lector a la entrada correspondiente en el Tesoro de Montoya, para acceder a los ejemplos que el autor no juzgó oportuno colocar en sus PhS. Otras veces, como en la entrada por la voz latina "seminare", 'eyaculación, polución', el autor no coloca "thes.". En el cuadro 3 (véase archivo en pdf en Documentos anexos a este artículo) hay algunos ejemplos que ilustran esta observación.

\section{El contenido de la obra}

En cuanto al contenido, las PhS, que equivalen aproximadamente a tres cuartos del total del Tesoro en número de páginas, en general, tienen también menos ejemplos y consecuentemente aportan menos datos etnográficos que el Tesoro. Como ya indicamos arriba, se vivía en una época más estable en las reducciones (Melià 2003, p. 112).

Presentamos en dos columnas los ejemplos del Tesoro y de las PhS para dos términos de suma importancia tanto a inicios como al final del siglo XVII: tape y pía. En el Tesoro preponderan estos dos términos con el significado de 'camino': tape (hape, rape, gupe, pe), y pía (vía, mbía). Ambos términos son colocados por el autor de las PhS en la entrada "Camino para cualquier parte". Empezamos por el término pía. Destacamos en negrita las diferencias entre una fuente y otra, en el cuadro 4 (véase archivo en pdf en Documentos anexos a este artículo).

Como puede verse, en las PhS hay mucho menos ejemplos que en el Tesoro. Los siete ejemplos donde pía significa 'enviar por' y 'enviar en busca de alguien o algo' no constan en las PhS. Todos los ejemplos del campo religioso del Tesoro reaparecen en las PhS. O sea, en los ejemplos estudiados, cambia el léxico cotidiano pero no el religioso.

Las diferencias lingüísticas observadas en estos ejemplos son la pérdida del sonido consonantal final como en $k o g$ que pasa a ser $k 0^{22}$, el marcador de negatividad e'ỹ, 'sin', pasa a ser separado del término al cual modifica y aparentemente sin corte glotal eỹ. Una modificación del marcador de intensidad de ite ite para itate etei y un cambio lexical de ýi gue para ky'a kue; ýi gue significa, en el Tesoro, 'sucio', no 'suciedad' ni 'basura'.

Pía aparece también con el significado de 'desvío', de 'apartamiento de camino' y de 'apartarse'. En el Tesoro, el término aparece en esa acepción en la misma página. En las PhS, aparece en la entrada "apartarse". Como puede observarse en el cuadro 5, para dieciséis ejemplos en el Tesoro, hay tres en las PhS (véase archivo en pdf en Documentos anexos a este artículo).

En aropía puede observarse una diferencia en la traducción. Mientras en el Tesoro consta como 'apartarse él, llevándolo consigo', en las PhS el mismo verbo es traducido por 'apártome con él'. Ninguna de las dos traducciones deja claro que se trata de la acción 
'desviar' (-pía) ejercida por la primera persona (a-) sobre una tercera persona (-ro-), que debe ser traducida por 'lo hago desviar y yo lo sigo en ese camino'.

Pasemos ahora al segundo término que indica camino, tape (hape, rape, gupe, pe). Para un total de 85 ejemplos en el Tesoro, hay 36 en las PhS. Transcribimos en el cuadro 6 solamente los ejemplos que tienen correspondencia en ambas fuentes (véase archivo en pdf en Documentos anexos a este artículo).

Las diferencias mínimas en estos ejemplos se pueden resumir como sigue:

\begin{tabular}{|l|l|l|l|l|l|l|l|l|l|l|l|l|}
\hline Tesoro & atu & Kue & ñeme'ẽngáva'e & me'ẽnge & ngi & pe'e'ỹ & re'ỹ & \multicolumn{2}{|l|}{ rĩni } & \multicolumn{2}{|l|}{ týva } \\
\hline $\begin{array}{l}\text { Phrases } \\
\text { Selectas }\end{array}$ & Aturi & kuéra & & ñemeẽngei & meẽnge'i & hávi & pe eỹ & $\begin{array}{l}\text { ri } \\
\text { eỹ }\end{array}$ & rini & ty \\
\hline
\end{tabular}

El resumen muestra que disminuyen las señales diacríticas; así, hay menos indicadores de corte glotal y hay menos tildes ${ }^{23}$. En consecuencia, hay más encuentros vocálicos del tipo $e e, e i$. Algunas partículas, al perder la consonante final, pierden una sílaba. Otras, con la entrada de la $i$ adquieren una sílaba más.

En cuanto a las diferencias en el contenido, los ejemplos que $P h S$ no retoma del Tesoro son: los caminos relacionados con las hormigas, con los animales salvajes en general, con las víboras, con los antas, así como con el camino de los astros. El Tesoro tiene muchos más vocablos que las PhS para describir los caminos. Ellos pueden ser cortos, largos, llenos de hoyos, bien hechos, planos, anchos, estrechos, con subidas, pantanosos, muy usados, poco usados, abandonados. Pueden conducir al río, al bosque, a la casa, al puerto, al otro, al cielo, al infierno, a Dios, al diablo. Los ejemplos dicen también de las experiencias de quienes frecuentan los caminos.

¿Qué omiten las PhS? Además de las partículas listadas al final del manuscrito, se omiten "vocablos en castellano" y todos los ejemplos relativos a lo que el autor considera "menos limpio", lo que recae sobre actividades erótico-sexuales, como "corromper, desflorar o otros (sic) semejantes", sobre la anatomía y acciones "menos nobles" del cuerpo. ¿Por qué esta omisión? La primera, según el autor, "para que los escribanos no hallen en que tropezar" (PhS, Amigo en Cristo). Si el lector desea acceder a los términos "menos limpios", el autor lo remite al Tesoro de Ruiz de Montoya ${ }^{24}$. Esto indica otro criterio usado por el autor para reestructurar el Tesoro, un criterio moral.

En cuanto a la supresión de "algún vocablo en castellano", parece no haber sido a propósito, ya que el autor recomienda y explica: "búscalo en otro sinónimo, y lo hallarás" (PhS, Amigo en Cristo y benévolo lector). O sea, aparentemente, el argumento no es lingüístico.

Volvamos ahora a las PhS como una fuente que es más que un compendio de doctrina y que en eso mantiene la característica de los diccionarios anteriores del guaraní. Como puede ser comprobado en los capítulos seis a diez y en el anexo II de Decir el Cuerpo (Chamorro 2009), los diccionarios de Montoya ofrecen un vasto y diversificado número de datos que sobrepasan de lejos el interés estrictamente doctrinario catequético, pudiendo cubrirse con ellos casi todo el cuestionario científico (Melià 1988, p. 43) de la antropología contemporánea, como también lo ha mostrado Antonio Caballos (2013) en su Etnografía Guaraní según el Tesoro de la lengua guaraní de Antonio Ruiz de Montoya. 

diversos tipos de cestos. Hay términos para cestos duplos, cesto grande, de cuatro palos, pequeño, con asideros $u$ orejas, muy tejido, con labores, blanco, semejante a tortuga, con la base puntiaguda, pequeño hecho de palmas, tejido de forma muy rala, muy ralo, medio cesto usado por las mujeres, cesto hecho de cañas y parecido a un plato grande $(T, 11,25$, $178,261,342,362,404,406)$. Hay expresiones sobre técnicas relativas a la cestería como ajapysa ypy'o, 'poner fortaleza a la punta, de cesto' $(T, 52)$, aipya ajaka, 'tejer cestos' $(T$, 288), ahevi rytakua, 'atar al cesto el asiento con unas varillas' ( $T, 361)$, ahevirũ ajaka, 'dar principio al cesto' ( $T$, 344-345). También hay indicaciones sobre el uso cotidiano del objeto cesto, como en amboyapu ajaka ituvyróka, 'sacudir el cesto' $(T, 165)$, así como usos figurados de los vocablos relativos a cesto. Es el caso de ajaka rami nde kyra, 'estás muy gordo como un cesto' y oira ñãng ajakápe ipypy oĩna ñavẽvẽ, eguĩ javẽ ave ãnguéra añã ratakuára pype ipypy mburu okuápa, 'así como los peces están apretados en el cesto, así las almas están en el horno del infierno' $(T, 240)$.

En las PhS, la entrada es por "canasta y su variedad, o cesto". En este manuscrito hay tres nombres genéricos para cesto: ajaka, panakũ y urukuru. En ella se repiten ocho de las frases formadas con ajaka en la página 25 del Tesoro. Al final, el autor escribe "vide. Ajaka". No consta el cesto karumbe o 'tortuga'. Para munakũ consta el mismo ejemplo y más che mynakũ, 'mi cesto'. Para urukuru, el autor presenta un ejemplo nuevo: ourukuru pýpe oguenoae guembi'u, 'con su cesto trae su comida'. El autor remite a la entrada urukuru del 
Tesoro, pero en este no hay otros ejemplos. También en este tema hay menos datos etnográficos que en el Tesoro.

En una perspectiva de análisis que tensiona lo histórico-social (temporal) y lo espiritual (eterno), estos ejemplos relativos a ladrillos, adobes, tapias y cestos son del ámbito de lo temporal pues tienen que ver con técnicas, en parte nuevas, de la construcción, no solo de iglesias, sino también de casas. Tienen que ver con lo cotidiano del trabajo y de la subsistencia e implementación de un nuevo modo de vida. Son del ámbito temporal, pues la producción y el uso de estos dos elementos de la cultura material, así como las actividades que ellos impulsaban, estaban a cargo del sacerdote responsable de la administración de los bienes del pueblo "en lo temporal"; esto es, que intervenía directamente en la actividad económica, cultural, social y hasta militar de la comunidad.

En cada reducción había dos sacerdotes. Uno se encargaba de lo espiritual. Era el sacerdote del pueblo. El otro era "el compañero" y a su cargo estaba lo temporal, como la administración del trabajo y de la instrucción. Lo temporal está al servicio de lo eterno en la espiritualidad jesuítica. Y la obra de Juan Eusebio Nieremberg S. J., De la diferencia entre lo temporal y eterno. Crisol de desengaños con la memoria de la eternidad, postrimerías humanas y principales misterios divinos, impreso en guaraní, en 1705, en las reducciones jesuíticas, muestra precisamente que no se llega a lo eterno despreciando las cosas temporales y viviendo esta vida en una especie de añoranza de lo eterno. Como advierte Fernando Miguel Gil (2010, p. 39) en su introducción a la obra, "la 'diferencia' entre lo temporal y lo eterno está en relación con la finalidad de la vida (...). Las 'cosas sobre la haz de la tierra', lo temporal, son medios que se deben 'usar' para alcanzar el fin, o sea la eternidad feliz junto a Dios".

55 En ese sentido, los jesuitas lingüistas y los indígenas - desde el comienzo de la misión y no solo en el siglo XVIII, como observan Cerno y Obermeier (2013, p. 50) - aplicaron también el conocimiento lingüístico al servicio de campos ajenos a la religión. Ellos crearon en guaraní o tradujeron al guaraní no solo los vocablos y las formas de hablar correspondientes al campo religioso sino también los concernientes a la nueva forma de vida, subsistencia, organización social y prácticas culturales. De modo que las PhS como las obras lingüísticas anteriores estuvieron preñadas de la relación eterno-temporal.

La última observación que nos gustaría presentar en cuanto al contenido de las $\mathrm{PhS}$ son las diferencias dialectales notadas por el autor del manuscrito entre las lenguas guaraníes de su época y entre estas y las formas registradas unas ocho décadas antes en el Tesoro. A nuestro modo de ver, ellas pueden derivar del hecho de que esas obras se apoyaron en comunidades étnicas que no hablaban exactamente la misma lengua guaraní y en algunos casos aprendieron el guaraní como segunda lengua en las reducciones ${ }^{26}$. Montoya se apoyó en la lengua de los pueblos de la región del Guairá (Melià 1998), mientras que las formas de hablar que están en la base de las PhS probablemente fueron las del Tape y las de las reducciones ribereñas del río Uruguay (Melià 2003, p. 112, Chamorro 2009, p. 70). En particular, las reducciones de Santa María la Mayor y San Xavier son las más nombradas en el manuscrito. Ese hecho sumado al uso constante de la expresión "no se usa en Santa María ni en San Javier" indica, en nuestra opinión, que el autor de las PhS tomó como referencia las formas de hablar de esos pueblos. Las varias lenguas guaraníes habladas hasta hoy, entre otros, por los pueblos indígenas Avá-Guaraní (Ñandéva), Kaiowá o Paĩ-Tavyterã y Mbyá - de las regiones bañadas por los ríos Paraná, Paraguay y Uruguay y sus afluentes, en Argentina, Brasil y Paraguay- nos ayudan a imaginar la diversidad lingüística en la zona misionera, en el siglo XVII. Aunque de forma parcial y en distintos 
niveles de interacción, sus ancestros tuvieron contacto con los jesuitas o fueron reducidos por ellos y ciertamente habrán aportado sus modos de hablar al nuevo orden social que se establecía. Entre las diferencias que podemos constatar hoy día entre kaiowa y mbyá destacamos algunas del ámbito del vocabulario y otras de la fonología.

\begin{tabular}{|c|c|c|c|}
\hline \multicolumn{2}{|c|}{ Diferencias lexicales } & \multicolumn{2}{|l|}{ Diferencias fonológicas } \\
\hline mbya & kaiowá & mbya & kaiowá \\
\hline $\begin{array}{l}\text { pygua kuéry, } \\
\text { familia }\end{array}$ & $\begin{array}{l}\text { tetarã; te'ýi; ñemoñã, parientes; familia; } \\
\text { descendencia }\end{array}$ & $\begin{array}{lr}\text { 'ãgue, } & \text { 'ãgue; } \\
\text { ñemokuaray'ã; eco, } \\
\text { sombra, } r \text { alma } \\
\text { penada, hacerse } \\
\text { sombra }\end{array}$ & $\begin{array}{l}\text { 'ãngue;hi'ãngue; } \\
\text { ñembokuarahy'ã; } \\
\text { eco, sombra, alma } \\
\text { penada, hacerse } \\
\text { sombra }\end{array}$ \\
\hline $\begin{array}{l}\text { xeryke'y tujave } \\
\text { va'e, mi } \\
\text { hermano más } \\
\text { viejo }\end{array}$ & $\begin{array}{l}\text { che ryke'y, mi hermano más viejo, che } \\
\text { ruvicha, mi hermano principal }\end{array}$ & $\begin{array}{l}\text {-emiarirõ, nietos y } \\
\text { nietas de la abuela; } \\
\text {-amyminõ, nietos y } \\
\text { nietas del abuelo }\end{array}$ & $\begin{array}{l}\text { temiarirõ, nietos y } \\
\text { nietas de la } \\
\text { abuela; temiminõ, } \\
\text { nietos y nietas del } \\
\text { abuelo }\end{array}$ \\
\hline $\begin{array}{lr}\text { xeregua, } & \text { mi } \\
\text { hermano } & \mathrm{o} \\
\text { hermana } & \end{array}$ & $\begin{array}{l}\text { tyke, che ryke, che kypy'y, hermana } \\
\text { mayor y hermana menor, siendo ego la } \\
\text { mujer; teindy; che reindy, hermana, } \\
\text { siendo ego el hombre }\end{array}$ & $\begin{array}{l}\text { ojogueraa, se llevan } \\
\text { mutuamente }\end{array}$ & $\begin{array}{l}\text { ojogueraha, se } \\
\text { llevan } \\
\text { mutuamente }\end{array}$ \\
\hline $\begin{array}{l}\text { xera'y japyre'i, } \\
\text { mi último hijo }\end{array}$ & che ra'y pahague, mi último hijo & $\begin{array}{l}\text { vy'aa, lugar de } \\
\text { alegría }\end{array}$ & $\begin{array}{l}\text { vy'aha, lugar de } \\
\text { alegría }\end{array}$ \\
\hline $\begin{array}{lr}\text { ta'y } & \text { kyrĩ; } \\
\text { xera'y } & \text { kyrĩ, } \\
\text { sobrino } & \text { del } \\
\text { hombre } & \end{array}$ & $\begin{array}{l}\text { atipe kuéry, jetipe, che ryke'y ra'y, } \\
\text { sobrino del hombre }\end{array}$ & $\begin{array}{l}\text { ajaka py ugwa, cesto } \\
\text { hondo }\end{array}$ & $\begin{array}{l}\text { ajaka pygwa, cesto } \\
\text { hondo }\end{array}$ \\
\hline $\begin{array}{lr}\text { tajy } & \text { kyrí; } \\
\text { xerajy } & \text { kyrí, } \\
\text { sobrina } & \text { del } \\
\text { hombre } & \end{array}$ & $\begin{array}{l}\text { atipe, xe ratipe, che ryke'y rajy, sobrina } \\
\text { del hombre }\end{array}$ & $\begin{array}{ll}\text { aru ruka, hago } \\
\text { traer }\end{array}$ & $\begin{array}{l}\text { aru uka, agueru uka } \\
\text {, hago traer }\end{array}$ \\
\hline $\begin{array}{l}\text { yvytu ava ete, } \\
\text { viento } \\
\text { peligroso }\end{array}$ & (yvytu) marãny, viento destruidor & poropoanoa, médico & $\begin{array}{l}\text { poropohanohára, } \\
\text { médico, chamán }\end{array}$ \\
\hline
\end{tabular}




\begin{tabular}{|c|c|c|c|}
\hline $\begin{array}{l}\text { ovaja, cuñada } \\
\text { en general }\end{array}$ & $\begin{array}{l}\text { tyvy raty, cuñadas o cuñados, siendo } \\
\text { ego el hermano mayor; tembireko ryke } \\
\text { o tembireko kypy'y, hermanas mayores } \\
\text { o menores de la esposa; tyke'ýra raty, } \\
\text { cuñadas o cuñados, siendo ego el } \\
\text { hermano menor en relación a su } \\
\text { hermano mayor; uke'i, las hermanas } \\
\text { del marido y las esposas del cualquiera } \\
\text { de los hermanos; ojouke'i es el } \\
\text { parentesco entre cuñadas }\end{array}$ & $\begin{array}{l}\text { ovaixĩ, ovaexĩ, } \\
\text { encontrar con }\end{array}$ & $\begin{array}{l}\text { ohovaitĩ, ohovaetĩ, } \\
\text { recibir a alguien o } \\
\text { encontrarse con } \\
\text { él }\end{array}$ \\
\hline $\begin{array}{l}\text { éry ka'aguy, su } \\
\text { nombre de la } \\
\text { selva }\end{array}$ & itupã réry, su nombre divinizador & syy, madre & sy, madre \\
\hline $\begin{array}{l}\text { omemby } \\
\text { oikuavã, dio a } \\
\text { luz }\end{array}$ & omemby ho'a, dio a luz & $\begin{array}{l}\text { moguera, mbokuera, } \\
\text { curar }\end{array}$ & monguera, curar \\
\hline $\begin{array}{l}\text { anga'i, magro, } \\
\text { seco; xe anga'i, } \\
\text { sou magro, } \\
\text { sou seco }\end{array}$ & $\begin{array}{l}\text { piru, seco, magro; che piru, sou magro; } \\
\text { seco }\end{array}$ & ange, ange' $i$, ahora & $\begin{array}{l}\text { ãga, ange, ko'anga, } \\
\text { ahora }\end{array}$ \\
\hline
\end{tabular}

\section{Consideraciones finales}

57 En este artículo introductorio a las PhS problematizamos el tema de la autoría. Concluimos que para avanzar en ese debate, entre otros pasos a dar, hay que comparar las PhS con el Vocabulario y el Arte de Restivo y con los manuscritos que supuestamente fueron el borrador de estas dos obras publicadas. En el interior de estos documentos pueden encontrarse datos lingüísticos que ayudan a fundamentar la adjudicación de la obra a Restivo o a otro jesuita. Como eso es algo por hacer, optamos por mantener el documento como de autoría anónima.

La comparación de las PhS con el Tesoro muestra que ambas fuentes son parte de un sistema político y religioso en el cual las diversas formas de hablar del guaraní debían ser estandarizadas. En este contexto, mucho más que registrar la diversidad de las lenguas, lo que los misioneros lingüistas tenían que hacer era uniformizar esa diversidad. En la época de Ruiz de Montoya, cuando las reducciones estaban en su fase inicial, esta tarea era mucho más urgente y determinante para la misión. Aun así, él no dejó de registrar las particularidades de la lengua, inclusive argumentando que con eso facilitaba el trabajo misionero. Ya a fines del siglo XVII, cuando las reducciones estaban más consolidadas y los modos de vida y de hablar estaban bastante homogenizados, se empezó a enfatizar las diferencias lingüísticas particulares que subsistieron a la normalización o surgieron acompañando los cambios sociales y la composición étnica de las reducciones. La referencia lingüística del autor del Tesoro es el antiguo Guairá y la de las PhS es la ribera del río Uruguay. 
59 En este contexto hay que tener presente que cuando los autores hablan del "desuso" de un vocablo estamos delante de un cambio social y cultural, que en la época de las PhS era probablemente mayor que el cambio ocurrido en los años de elaboración del Tesoro. Así, podemos imaginarnos que si en las $\mathrm{PhS}$ no tenemos expresiones que relacionen los caminos con animales y astros es porque el medio ambiente, las referencias y los usos sociales de ese elemento cultural habían cambiado. Y el hecho de registrarse menos variedades de cestos en las PhS que en el Tesoro puede indicar que disminuyó la diversidad tecnológica y los usos de ese elemento cultural.

De modo que estudiar esas fuentes, comparando diversos aspectos culturales de los guaraníes misioneros en dos épocas distintas, puede ser un aporte interesante para la historia social y cultural de la lengua guaraní en las reducciones, así como para la historia de los hablantes de esa lengua. En ese sentido, cabe recordar que la escritura es una forma histórica de relación social, que acaba dando forma a las instituciones (Orlandi 2001, p. 8); el uso de fuentes como las Phrases Selectas en los estudios histórico-antropológicos es obviamente necesario y promisorio. La cuestión es cómo hacerlo si lo que tenemos en fuentes como la estudiada aquí son palabras y frases, en su mayoría cortas y descontextualizas, sueltas, sin más datos sobre el ambiente natural, social, psicológico, lingüístico, histórico y político.

61 Entendemos que para el uso de este tipo de fuentes en los estudios históricos de las ideas lingüísticas hay que tener claro, entre otros aspectos, las condiciones sociopolíticas de producción de la escritura en guaraní y la relación de lo escrito con las instituciones misioneras (Rodríguez-Alcalá 2007, p. 409). En los estudios históricos y antropológicos apoyados en fuentes como Phrases Selectas hay que considerar además otros géneros de documentos, contemporáneos a la fuente en estudio, en los cuales el medio ambiente y el contexto social como un todo están más explicitados. De igual modo, hay que intentar distinguir las frases que probablemente ya estaban en uso antes de la implantación de las reducciones -o antes de su transformación en verdaderos pueblos- de aquellas que fueron introducidas por los ignacianos; lo que ya formaba parte de las antiguas costumbres indígenas del nuevo modo de vida y de las nuevas formas de hablar en las reducciones (Chamorro 2009, Caballos 2013). Como en los estudios históricos y antropológicos importa sobre todo el significado de las frases, aunque la obra sea bilingüe consideramos importante el conocimiento de la lengua indígena para poder dialogar con el autor del documento. Y como la lengua guaraní es una lengua viva, hablada por diversos grupos indígenas y no indígenas, es importante considerar lo que los pueblos guaraní-hablantes contemporáneos extraen a través de formas de hablar y vocabulario semejantes a los registrados por los jesuitas.

62 En cuanto a la estructura de la obra, vimos que las PhS, a diferencia del Tesoro, se estructuran como un diccionario. En el Tesoro, la entrada es por el guaraní; en las PhS las entradas principales son en español, aunque a los ejemplos se les da entrada por el guaraní. En nuestro manuscrito, el lector es remitido constantemente al Tesoro para acceder a más ejemplos. Al buscar veinte temas elegidos aleatoriamente, observamos que en 19 casos el Tesoro aporta más ejemplos que las $\mathrm{PhS}$.

63 Según la tipología propuesta por Eni Orlandi (1990) al estudiar el discurso de los descubrimientos, los ejemplos de las PhS, los del Tesoro y los de las otras obras lingüísticas de la época podrían ser definidas como obras que tuvieron una doble función didácticoreligiosa y política; controlaban la catequesis de los indígenas y su subordinación a los misioneros. Como las misiones jesuíticas no estaban solo para bautizar a los indígenas 
sino también para formar con ellos una nueva sociedad, los ejemplos de las PhS mantienen la función de las obras anteriores de creación/traducción de un nuevo lenguaje, no solo para el ámbito de lo eterno sino también para el ámbito temporal.

Estamos ante de un texto escrito por un no indígena con apoyo de indígenas "de primera clase". Un estudio más minucioso de esta fuente en el ámbito de la lingüística tendría que tener en cuenta la insistencia del autor de este documento en el hecho de que la lengua había cambiado y que el Tesoro se había vuelto obsoleto. ¿A cuáles cambios se refería él? Aparentemente solo a cambios lexicales. Sin embargo, tendría que considerarse también la posibilidad de cambios sintácticos, morfológicos y semánticos. ¿Cuál fue la intensidad o proporción de esos cambios? ¿Cuáles cambios sociales estaban implicados o indicados en esos cambios lingüísticos? Son cuestiones para otro trabajo.

\section{BIBLIOGRAPHY}

Anónimo (1687). Phrases selectas y modos de hablar escogidos y usados en la Lengua Guaraní. Mss. San Xavier: Sacadas del Thesoro escondido que compuso el venerable padre Antonio Ruiz de nuestra compañía de Jesús para consuelo y alivio de los fervorosos misioneros principiantes en la dicha lengua. Prólogo, 3 fojas sin foliar. Texto 633. Índice, 5 fojas, sin foliar. Referencia: 14/4/41.

Caballos, A. (2013). Etnografía guaraní según el Tesoro de la lengua guaraní de Antonio Ruiz de Montoya. Asunción: CEPAG.

Cerno, L. y Obermeier, F. R. (2013). Nuevos aportes de la lingüística para la investigación de documentos en guaraní de la época colonial (siglo XVIII). Folia Histórica del Nordeste, 21, 33-56. Resistencia: IIGHI, IH CONICET, UNNE.

Chamorro, G. (2009). Decir el cuerpo: historia y etnografía del cuerpo en los pueblos Guaraní. Asunción: Tiempo de Historia.

Documenta Jesuítica. (oct. 2000). 6 (24): p. 7-9. Asunción: CEPAG.

Falkinger, S. (2008). Gramáticas y vocabularios de la lengua chiquit /chiquitana. Austria: Instituto para América Latina de Carintia. Texto no publicado.

Freitas, A. (2013). Reduções Jesuítico-Guarani. Espaço de diversidade étnica. São Bernardo do Campo: Nhanduti.

Furlong, G. (1993). Arte en el Río de la Plata 1530-1810. Buenos Aires: Editora Argentina.

Furlong, G. (1962). Misiones y sus pueblos de guaraníes. Buenos Aires: Teorema.

Gil, F. M. (2010). De la diferencia entre lo temporal y eterno. Crisol de desengaños con la memoria de la eternidad, postrimerías humanas y principales misterios divinos, de Juan Eusebio Nieremberg S. J. Introducción [en línea]. En J.E. Nieremberg, De la diferencia entre lo temporal y eterno. Primera edición facsimilar en conmemoración al Bicentenario de la Revolución de Mayo, Instituto Bonaerense de Numismática y Antigüedades, Bolsa de Comercio de Buenos Aires, Bolsa de Comercio de Rosario, 2010. Disponible en 
http://bibliotecadigital.uca.edu.ar/repositorio/investigacion/diferencia-temporal-eterno-juannieremberg.pdf. Fecha de consulta 19 de junio 2014.

Lemos, A. (1956). Curso de Tupi Antigo: Gramática, Exercícios, Textos. Rio de Janeiro: Livraria São José. Disponible en: http://biblio.etnolinguistica.org/barbosa_1956_curso

Maeder, E. (2001). Libros, bibliotecas, control de lecturas e imprentas rioplatenses en los siglos XVI al XVIII. En: Teología, 40 (77): 5-24.

Melià, B. (1969). La création d'un langage chrétien dans les réductions des Guarani au Paraguay. 2 v. Strasbourg, France, Université de Strasbourg (Thèse de doctorat en sciences des religions).

Melià, B. (1988). El guaraní conquistado y reducido: ensayos de etnohistoria. 2a. ed. Asunción: Centro de Estudios Antropológicos de la Universidad Católica (Biblioteca Paguaya de Antropología, 5).

Melià, B. (1992). La lengua guaraní del Paraguay. Madrid: Mafre.

Melià, B. (1993) Antonio Ruiz de Montoya y el Arte de gramática de la lengua guaraní. En A. Ruiz de Montoya, Arte de la lengua guaraní. Asunción, Centro de Estudios Paraguayos Antonio Guasch.

Melià, B. (1998). Antonio Ruiz de Montoya y la construcción de una lengua guaraní en el Guairá. En E. Schalemberger, As missões jesuíticas do Guairá (pp. 565-388). Anais das Jornadas Internacionais das Missões Jesuíticas. Marechal Cândido Rondon: EDUNIOESTE, .

Melià, B. (2002). Historia Inacabada futuro incierto. VIII Jornadas Internacionales sobre las Misiones Jesuíticas. Asunción, CEPAG, 601p.

Melià, B. (2003). La lengua guaraní en el Paraguay colonial. Asunción: CEPAG.

Melià, B. y Nagel, L. M. (1995). Guaranies y jesuitas en tiempo de las Misiones: una bibliografía didáctica. Santo Ángelo. Asunción: URI, Centro de Cultura Misiones, CEPAG.

Neumann, E. S. (2005). Práticas letradas Guarani: produção e usos da escrita indígena (Séculos XVII e XVIII). Rio de Janeiro, Universidade Federal do Rio de Janeiro. (Tese de Doutorado em História). Disponible en: http://www.dominiopublico.gov.br/pesquisa/DetalheObraForm.do? select_action=\&co_obra=107879

Obermeier, F. (2010). Wie und mit welchen Mitteln erforschte man südamerikanische Indianersprachen? Eine historische Fallstudie über die Verwendung von Buchmaterialien, Manuskripten und Digitalisaten fuer die Forschung zur Linguistik südamerikanischer Indianersprachen. Wolfenbütteler Notizen zur Buchgeschichte, 35 (2),167-183. Wiesbaden.

Orlandi, E. (1990). Terra à vista: Discurso do confronto: velho e novo mundo. São Paulo, Cortez; Campinas: Editora da Unicamp.

Orlandi, E. (2001). História das Idéias Lingüísticas: Construção do Saber Metalingüístico e Constituição da Língua Nacional, Campinas: Pontes / Cáceres: Unemat.

Pastells, P. (1923). Historia de la Compañía de Jesús en la provincia del Paraguay: Argentina, Paraguay, Uruguay, Perú, Bolivia y Brasil, según los documentos originales del Archivo General de Indias. v. 4. Extractados y anotados por el R. P. Pablo Pastells, Madrid: Libreria general de V. Suarez.

Restivo, P. (1996 [1724]). Arte de la lengua guaraní. Versión Digital, introducción y notas por Silvio Liuzzi.

Restivo, P. (2010 [1724]). Arte de la lengua guaraní. Versión digital con un facsímile de la edición de 1724, por Silvio Liuzzi. Disponible en:

http://celia.cnrs.fr/FichExt/Paleographies/Guarani/Guarani_intro.htm. Consulta 20 de mayo de 2014. 
Restivo, P. (1722). Vocabulario de la lengva gvarani compvesto por el Padre Antonio Rviz de la Compañía de Iesvs, revisto y aumentado por otro religioso de la misma compañía. Santa María la Mayor.

Rodríguez-Alcalá, C. (2007). L'exemple dans les grammaires jésuitiques du guarani, Langages, 2 (166):112-126. URL: www.cairn.info/revue-langages-2007-2-page-112.htm. DOI: 10.3917/ lang.166.0112.

Rodríguez-Alcalá, C. (2013). El funcionamiento social de las tecnologías lingüísticas: Apuntes sobre la escritura en guaraní en la Provincia Jesuítica del Paraguay. En

S. Archaimbault, J-M Fournier y V. Raby (Ed.), Penser l'histoire des savoirs linguistiques. Hommage à Sylvain Auroux (pp.507-522). Lyon: ENS Edition.

Rodríguez-Alcalá, C. y Horta, N. J. (2008). Langues amérindiennes à la renaissance: norme et exemples dans les descriptions du tupi et du guarani. Histoire Epistemologie Langage, 30 (2), 25-70, Campinas: Unicamp.

Ruiz de Montoya, A. (1876 [1640]). Bocabulario de la lengua guaraní. Publicado nuevamente sin alteración alguna [por] Julio Platzmann. Leipzig: B.G. Teubner. BBI: 376p, BII: 234p. (Nueva edición, publicación y notas a cargo de Bartomeu Melià, Asunción: CEPAG, 2002).

Ruiz de Montoya, A. (1876 [1639]). Tesoro de la lengua guaraní. Publicado nuevamente sin alteración alguna [por] Julio Platzmann. Leipzig: B.G. Teubner. 409f. (Nueva edición, publicación y notas a cargo de Bartomeu Melià, Asunción: CEPAG, 2011).

Storni S.I, H. (1980). Catálogo de los Jesuitas de la Provincia del Paraguay (Cuenca del Plata) 1585-1768.

Roma, ARSI: Archivum Romanum Societatis Iesu.

Wilde, G. (2009). Religión y Poder en las Misiones de Guaraníes. Buenos Aires: SB.

\section{NOTES}

1. Agradecemos especialmente a André Freitas, Bartomeu Melià, Candida Barros, Capucine Boidin, César Itier, Joëlle Chassin, Isabelle Combès y Ruth Monserrat, por los datos aportados y por sus comentarios.

2. Hay otro manuscrito de 21.5 x $15.5 \mathrm{~cm}$ y 586 páginas, con ese mismo nombre y contenido en la Colección Peña, Archivo del Museo Udaondo de Luján, Argentina, bajo la referencia MSS. 091=873.241 CDJ. Este manuscrito está encuadernado en cuero, con canto dorado a la hoja, se encuentra en buen estado. En el lomo lleva el título en letras doradas y las letras MSS seguidas de un punto, como en otra obra de la colección Peña. La parte interna de la tapa y de la contratapa está cubierta con una página en colores, así como la siguiente. Siguen cinco páginas en blanco, las dos primeras con sellos, fechas y firmas. En el frontispicio de este ejemplar constan todos los datos legibles que se observan en la carátula del manuscrito del Museo Mitre, aunque distribuidos de forma distinta. No consta en él el rótulo en francés. En la siguiente hoja está el texto introductorio "Amigo en Christo y Benevolo lector", incluyendo las Advertencias. Luego los datos de la letra A hasta la Z, cubriendo las páginas de 1 a 586. No trae el texto inicial, ni el índice, ni la lista de vocablos presentes en el manuscrito del Museo Mitre. Agradecemos a Mariana Luchetti, responsable del Museo Udaondo de Luján, por los datos y por su apoyo a nuestra colega Cecilia Adoue, en misión en archivos de Argentina, por el proyecto de investigación LANGAS Lenguas Generales de América del Sur. Agradecemos igualmente a Cecilia por las copias del manuscrito.

3. Por eso las reducciones de la región suelen también ser llamadas “del Uruguay”, entiéndase, de la frente misionera en la cuenca del río Uruguay. 
4. Pablo Restivo nació en la comunidad de Mazzarino, provincia de Caltanisetta en la región de Sicilia, Italia, el 30 de agosto de 1658. Ingresó en la Compañía de Jesús el 20 de abril de 1677, en Sicilia. El 9 de febrero de 1689 partió para América del Sur, desde el puerto de Sevilla. Llegó a Buenos Aires el 6 de abril de 1691 y el 15 de agosto de 1694 a la reducción de Candelaria, entonces Paraguay, hoy Misiones, Argentina. Ahí él hizo profesión de los 4 votos, fue ordenado sacerdote y aprendió la lengua guaraní de las reducciones, mereciendo elogios ya en 1707. De las reducciones de los guaraníes, Restivo siguió para la actual Bolivia, donde trabajó en la misión de Chiquitos, de 1706 a 1712, desempeñándose como visitador provincial de dicha misión durante los dos últimos años (Tomichá 2002, p. 171). Fue rector del Colegio de Salta, Argentina, y misionero entre los chiriguanos de Bolivia, de 1715 a 1718. En ese país fue elogiado por haber aprendido muy bien el guaraní y la lengua chiquitana. Volvió a las reducciones del Paraguay, donde fue Superior General de las Misiones de Guaraníes, de 1718 a 1720, y rector del Colegio de Asunción, de 1723 a 1724. Desde este año hasta su muerte, el 11 de enero de 1740, vivió en el pueblo de Candelaria (Storni 1980, p. 236).

5. En este caso, el anagrama consiste en la transposición de todas las letras del nombre "Pablo" y del apellido "Restivo" para formar el nombre compuesto "Blas Pretovio".

6. La tercera parte de los jesuitas que partían al campo misionero podían ser "extranjeros", así entre comillas, porque de cierta forma eran también "españoles", pues sus países eran vasallos de la Corona española y "de los Estados hereditarios de la Casa de Austria" (Pastells IV, 1923, p. 224), entre los cuales constaban Hungría, Bohemia, Austria, El Tirol, Suabia, Alsacia. España mantenía en vigor una especie de concordato con esos Estados y los misioneros de esos parajes eran bien aceptados en América. Reclutados en sus provincias, eran enviados a Sevilla, donde proseguían sus estudios, mientras aguardaban el envío. Aprendían español y muchos incluso hispanizaban el nombre y el apellido; algunos adoptaban pseudónimos o anagramas para firmar sus obras. Los italianos procedían de los Estados Pontificios, o "reinos españoles", como Sicilia; fue el caso de Pablo Restivo. En 1690, de los 44 religiosos de partida al Paraguay, listados en la Casa de la Contratación de Sevilla, 21 eran de España, 9 de Italia, 9 de Flandes, 1 de Austria, 2 de Bohemia y 2 del Tirol.

7. Manuscrito autógrafo inédito, $180 \mathrm{~mm}$. $2 \mathrm{fsn}+229 \mathrm{p}+1 \mathrm{peb}+\mathrm{fsn}$, conservado en la Biblioteca Universitaria de Granada (España) BUG. Caja 38. Versión digital disponible en:

http://digibug.ugr.es/handle/10481/163/simple-search?query=\%22Arte+de+la+lengua+guaran\% C3\%AD\%22.

Una copia de este manuscrito, Arte de la lengua Guaraní por Blas Pretovio, fechada también en 1696, se encuentra en el Museo Mitre, Catálogo, 94.

8. Uruguay es aquí una referencia al río Uruguay en cuyas proximidades se erguían, entre otras, las reducciones de Concepción, Santa María y San Javier.

9. El original se encuentra en el Museo Mitre de Buenos Aires, Catálogo, II, 94. Parte de este manuscrito está bajo el título Partículas de la lengua Guaraní por el Padre Blas Pretovio de la Compañía de Jesús. Número 3092, en el Museo Histórico Nacional de Buenos Aires, conforme consta en el Catálogo de Documentos del Museo Histórico Nacional, Buenos Aires, 1952, t. III, p. 202 (Melià 2003, p. 332). Actualmente este se encuentra dividido entre el MHN y el AGN. En el AGN se encuentra en la Sala VII, Colección MHN legajo 65, Número de Catálogo 10747, también bajo el número 3092 que va sellado en las páginas, clichés P1040 908 al 918. En el MHN, se encuentra bajo el número 3092, AHMN, FDA/FG/SecTr/R44/309 - Clichés P1040 858 a 891. Agradecemos esta información a la señora Sofía Oguic, responsable de archivos en el Museo Histórico Nacional de Buenos Aires, y a Cecilia Adoue, por compartirla con nosotras.

10. De aquí en adelante PhS.

11. Cabe notar que los misioneros "lingüistas", incluyendo a Anchieta, "mostraron clarividencia e intuición de muchos fenómenos específicos de la lengua” (Barbosa 1956, p. 22). La traducción del portugués al español es nuestra. 
12. De aquí en adelante $(T)$ en las referencias.

13. La grafía original de los términos y de las expresiones extraídos de las fuentes fue alterada siguiendo la tabla de correspondencia propuesta por Melià (1993), en la reedición del Arte de la Lengua Guaraní, de Ruiz de Montoya.

14. La estabilidad demográfica era resultado de la reproducción de los indígenas ya reducidos y no de la incorporación de nuevos indígenas a las reducciones ya existentes o de la fundación de nuevas reducciones (Freitas 2013; Melià y Nagel 1995).

15. En 1630, el padre Juan Bautista Ferrufino, procurador de los jesuitas de la provincia del Paraguay, partía a Madrid y Roma, entre otros encargos, para interceder por "una imprenta para publicar varias obras en lengua indígena, sumamente necesarias", pedido que él presentó, en 1632, al General de la orden (Furlong 1993, p. 5; Gil 2010, XXXIV).

16. El padre Juan Bautista Neumann, nacido en Viena en 1659 y llegado a Buenos Aires con Sepp y Restivo en 1691, juntamente con el padre José Serrano, nacido en Málaga en 1634 y llegado a Buenos Aires en 1658, armaron la imprenta, fundieron los tipos necesarios e imprimieron los primeros libros, lo que se hizo en las reducciones de Nuestra Señora de Loreto, San Javier y Santa María la Mayor (Pastells y Mateos 1912-49, IV, p. 237). Maeder (2001, p. 20-23) lista nueve obras existentes- salidas de la imprenta de las reducciones jesuíticas. Seis son de contenido netamente religioso: 1) Martirologio romano (1700), 2) De la diferencia entre lo temporal y eterno (1705), 3) Instrucción práctica para ordenar santamente la vida (1713), 4) Manuale ad usum Patrum Societatis Iesu, qui in reductionibus Paraquariae versantur ex Rituali Romano ac Toletano decerptum (1721), 5) Explicación del catecismo en lengua guaraní por (1724), 6) Sermones y ejemplos en lengua guaraní... (1727). Hay otras tres obras que no son de contenido estrictamente religioso; dos de ellas son técnico lingüísticas: 7) Vocabulario de la lengua guaraní (1722) y 8) Arte de la lengua guaraní (1724), mientras la última es de cuño más político: 9) Carta que ... el señor doctor don Joseph de Antequera y Castro ... escribió ... al obispo (1727).

17. Diario hecho por un indio de lo que sucedió en el segundo desalojamiento de los portugueses [de la Colonia de Sacramento] en 10 de septiembre de 1704 [hasta el 18 de marzo de 1705] (Melià 2002, p. 217-222).

18. El manuscrito se encuentra en la Biblioteca de la Universidad de Pennsylvania, bajo la referencia UPenn Ms. Coll. 700, item 215.

19. Un ejemplar del manuscrito se encuentra en la Wellcome Library (YHSA. 43) y otro ligeramente distinto y aparentemente más completo se encuentra en la Biblioteca Nacional de España (BNE, MSS/22992). Para una introducción al manuscrito, consultar el artículo de Angélica Otazú, en este mismo dossier sobre fuentes en lenguas indígenas, revista Corpus (v. 4, n. 2, 2014), el artículo de Obermeier (2010) y el artículo de Cerno y Obermeier (2013).

20. Publicado en Buenos Aires: Edición de la Biblioteca Nacional de Buenos Aires, 1945. Disponible en internet bajo http://www.bvp.org.py/biblio_htm/montenegro/monteneg.htm

21. El prefacio de la obra fue publicada por Garzón Maceda, en el libro La Medicina en Córdoba (1916).

22. Este cambio es frecuente pero no constante. Añanng (PhS, 156), por ejemplo, aparece con la consonante final $g$, que indica el sonido consonantal gutural que en las lenguas emparentadas del litoral aparecen generalmente como Añannga.

23. En el caso del Tesoro, nos basamos en las indicaciones, aunque no regulares, del autor; en el caso de las Phrases Selectas, en nuestra transcripción/interpretación del texto manuscrito.

24. De cierta forma Montoya también "escondió" muchos de estos términos de los lectores comunes al escribirlos en latín, lengua que daba un velo científico y moral al nombrar los órganos sexuales y sus adyacencias así como las funciones de esos órganos.

25. Vale registrar que en el Vocabulario de Restivo (1722) esos términos aparecen, lo que es indicio de un probable uso del término en el siglo XVIII. 
26. Aunque la entrada de las poblaciones indígenas no guaraní ni guaraní-hablantes en las reducciones no sea un dato transparente y explícito en las fuentes, investigaciones como la de André Freitas (2013) muestran la composición pluriétnica de las reducciones.

\section{INDEX}

Keywords: Manuscripts on Guarani, Selected Phrases, History of the Guarani language, Indigenous History, Jesuits in Paraguay.

Palabras claves: Manuscritos en Guaraní, Phrases Selectas, Historia de la Lengua Guaraní, Historia Indígena, Jesuitas en el Paraguay

\section{AUTHOR}

\section{GRACIELA CHAMORRO}

Universidade Federal da Grande Dourados (UFGD), Coordenação de Aperfeiçoamento de Pessoal de Nível Superior (CAPES), Brasil y Centre de Recherche et de Documentations sur l'Amérique (CREDA), Francia.

Correo electrónico: candidaarguello@ufgd.edu.br 